\title{
Missed Pauses and Everyday Interactions for Migrant Indian women during Covid- 19 Times
}

\author{
SriPallavi Nadimpalli \\ University of Melbourne, Australia \\ snadimpalli@student.unimelb.edu.au
}

\begin{abstract}
The time-space activities for women largely emerge from the relational needs and demands of others in their lives. Davies (2003) explains that as women take on multiple roles in both public and private spheres, they often have limited time for a pause. Drawing from Snow and Brissett (1986), Davies explains that these pauses are moments of relaxation, re-energising or reflection, which are essential for an individual's wellbeing. Findings from 20 interviews conducted with migrant women in Hyderabad, India, showed that these pauses were necessary and integral to their everyday spatial routines at home and work. In addition to giving respite from daily chores at home, pauses helped establish social connections and form an attachment with a new place as migrants. This paper reflects on how these pauses can be impacted during COVID-19 times, especially when migrant women continue to experience an increased share of responsibilities at home due to patriarchal expectations and limited movement outdoors due to the lockdown restrictions in India.
\end{abstract}

Keywords: migrant women, Indian, pauses, everyday interactions, COVID-19

To cite this article:

Nadimpalli, A. (2020). Missed Pauses and Everyday Interactions for Migrant Indian Women during Covid-19 Times, The Journal of Public Space, 5(3), II5-I20, DOI 10.3289I/jps.v5i3.I295

This article has been double blind peer reviewed and accepted for publication in The Journal of Public Space. 
Within the time-geography approach, originally developed by Torsten Hägerstrand, all individual activities take place in time and space, which form the basic constraints or enabling factors that affect freedom of action and movement. Feminist researchers, however, have argued that, unlike men, women's freedom of choice to use their time and space is gendered and is "substantially influenced by the interlocking of the public and private spheres and by women's structural position in these spheres" (Davies 2003, p.135). Most women have complex daily patterns owing to multiple roles and overlapping responsibilities that combine caregiving, domestic chores in addition to paid work, which impacts their everyday access and use of space (Law 1999; Davies 2003; Whitzman 2013).

Feminist researchers have primarily attributed this differential access to space and everyday mobility to the traditional divide between public and private spaces, which translates into expected behavioural norms based on gender (for example, see Rose 1993; Phadke et al. 20 I I). Patriarchy and societal expectations sometimes require women to demonstrate purpose and legitimacy while using public spaces, which are traditionally understood as masculine. Law (1999) explains that embodied skills conditioned by social practices also impact mobility choices available and elected by women. This further impacts on women's access to economic and social resources (Law 1999; Whitzman 2013). While these are some of the predominant factors that influence the everyday movements of women, other factors could emerge based on the context and how different identities are recognised and positioned within them. In this paper, I draw on the work of Karen Davies (2003), who forefronts the rationality of care in understanding the time-space activities for women in both public and private spheres. Unlike the linear conceptualisation of time, proposed by Hägerstrand's timegeography, women's activities often consist of multiple activities occurring simultaneously with overlapping temporalities with limited scope for a pause (Davies 2003). Here, pauses are defined as "moments at work or home when the usual flow of work is halted for a period" (Davies 2003, p. 140). Drawing from Snow and Brissett ( 1986$)$, Davies explains that pauses are not necessarily a period of inactivity but can be moments of relaxation and re-energising or reflection, which are essential for an individual's well-being.

In this paper, I examine the narratives of 20 migrant women interviewed in Hyderabad, India to understand the nature and significance of these pauses in their lives. Migrant women often experience multiple barriers to integration (including social, cultural and structural) in their receiving cities. The research findings suggest that pauses have not only granted respite from everyday chores but it also helped the migrant women build a connection with their new home through their routine practices. This paper reflects on these findings to understand how pauses can be altered in COVID-19 times and impact the everyday life of migrant women.

\section{The context}

A total of 20 interviews were conducted in Hyderabad, India, during early 2018. These interviews were a part of a doctoral thesis examining spaces of belonging for migrant Indian women as internal migrants in India and as international migrants to Australia. This paper only focuses on some of the key findings from the Hyderabad case. While the interviews were conducted before the pandemic, the findings are relevant and 
important for understanding the differential impact of COVID-19 on particular social groups, especially those who are marginalised.

Hyderabad is the joint capital of the state of Telangana and Andhra Pradesh, with a population of 7.67 million (Census of India $20 \mathrm{II}$ ). The migrant women interviewed were residents of Gagillapur, which is a peri-urban area in the north-west of the city. Gagillapur has primarily attracted rural migrants (both inter- and intra-state) due to its established industrial area, which offers employment opportunities. Also, the area is rapidly urbanising due to the expanding city limits.

Almost all the participants interviewed were married with children, and their ages ranged between $25-65$ years. Most of them attended school and received some basic education, except for three uneducated participants. However, there was only one participant who graduated high school and had a diploma. The predominant reason for their migration was stated as marriage or job opportunities (primarily for the spouse). Other reasons included escaping hardships, like drought or family feuds in the hometown, or migration with parents during childhood. No independent migrations were stated.

Most women in Gagillapur identified managing home, undertaking domestic chores and caring for their family as their primary responsibility. Seven participants were also simultaneously engaged in small home-based businesses (like tailoring) or entrepreneurial activities (like operating a mini-grocery store or a food stall or cart) with their spouses. One other participant worked as a community resource person with an NGO.

\section{Everyday Movements}

The participants were asked to describe different spaces that were part of their routine activities to understand their importance in their daily lives. Most frequently recurring time-space routines were core activities related to I) work, 2) purchasing necessities (like groceries, vegetables, government subsidised rations), 3) caregiving activities (like domestic chores or care-related trips, like chaperoning children to schools) or 4) trips to places of worship. Social interactions, as part of restorative activities, also recurred at varying frequencies in multiple locations to accommodate both casual and meaningful interactions. Other restorative trips included travel for leisure, religion or visiting family and relatives both within and beyond Hyderabad.

Core activities, however, occurred in combination with social interactions and rarely as an isolated, separate event. For example, women often completed their essential purchases or daily chores in small groups (where possible) to socialise simultaneously. The rationality of care appeared to be an integral part of their lives due to the gender normative expectations both within the public and private spheres. For most women, trips outdoors were also limited to purchasing necessities and care-related activities. Also, as most of the women interviewed did not drive, they preferred tasks that could be completed independently (or in small groups) and within short walking distances from home. Overall, as the migrant women prioritised their needs of their families before theirs, there was limited scope for pauses in their time-space routines. 

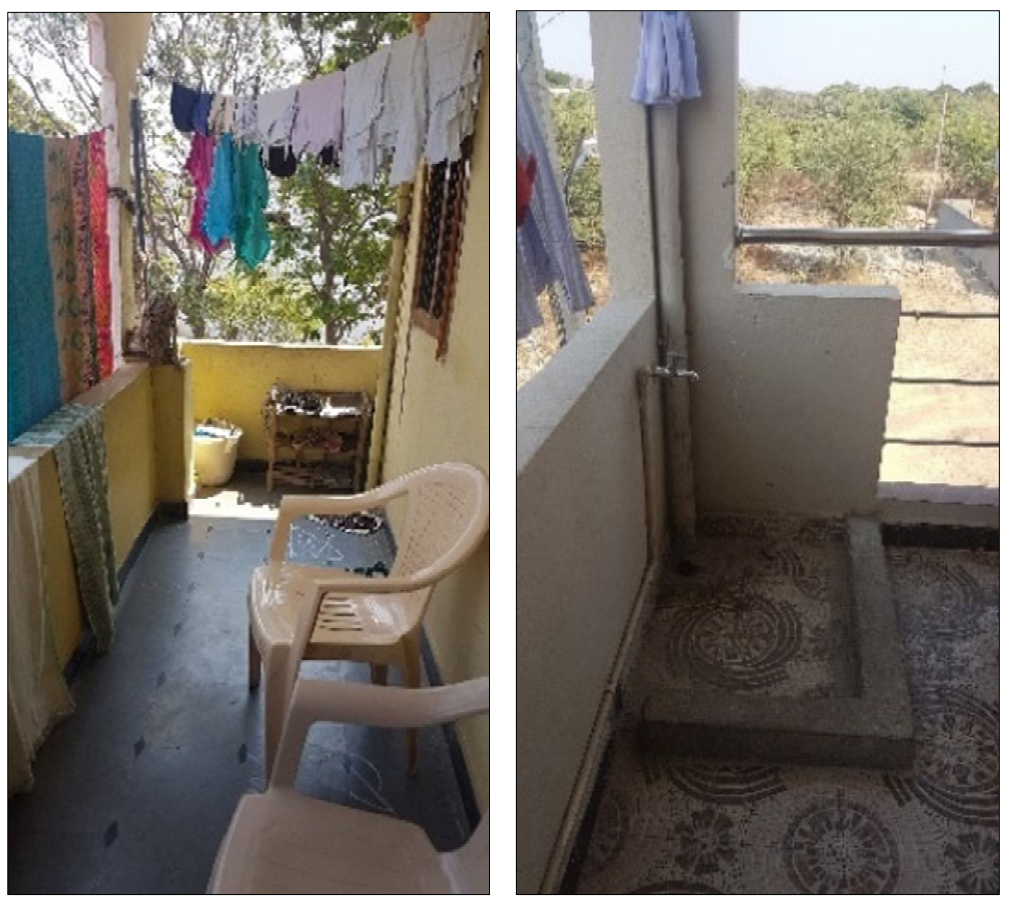

Figure I. Corridor spaces in a multi-tenant building. Left: outdoor seating, right: laundry or meat cleaning corners (Picture by the author)

\section{Pauses}

Home and its vicinity (like the doorstep and front porch) served as an important social space when the migrant women got together in small groups during mid-day. These interactions were accommodated during a brief period, in-between morning and evening chores when their children and spouse were away. One participant explained that catching up at the doorstep was convenient as "everyone can get resume their work", even if they take a quick break from their busy routines.

Similarly, the women utilised corridor spaces within multi-tenant apartments during this "free" time to co-ordinate their daily chores, like washing clothes or doing prep-work for cooking and socialise (see Figure I). These pauses made mundane tasks pleasurable by making them a collective activity.

Some of the participants also stated that as their children got older, they could pursue other interests. These pauses expanded and transformed into time and space for homebased businesses for at least two participants, who worked as professional tailors from their living rooms. Some women chose to utilise this time to pursue other hobbies and interests.

In the public sphere too, most core-activities were co-ordinated between friends and neighbours. For example, some participants chaperoned their young children to school every day and sometimes delivered lunchboxes in the afternoon. These short walks were also utilised for socialising between mothers. Tuan (1979) explains that established paths and routes part of a routinised activity, form a habit field which often require minimal decision making to navigate. These habit fields aid in developing an affective bond with a place. For migrant women, it was particularly important to build multiple habit fields in their new environment, to build familiarity. Some other habit 
fields were weekly walking trips to an informal vegetable market, which was organised every Wednesday in Gagillapur (See Figure II). In addition to purchasing vegetables and knick-knacks, the market presented opportunities for socialising and eating at the food stalls with other women.

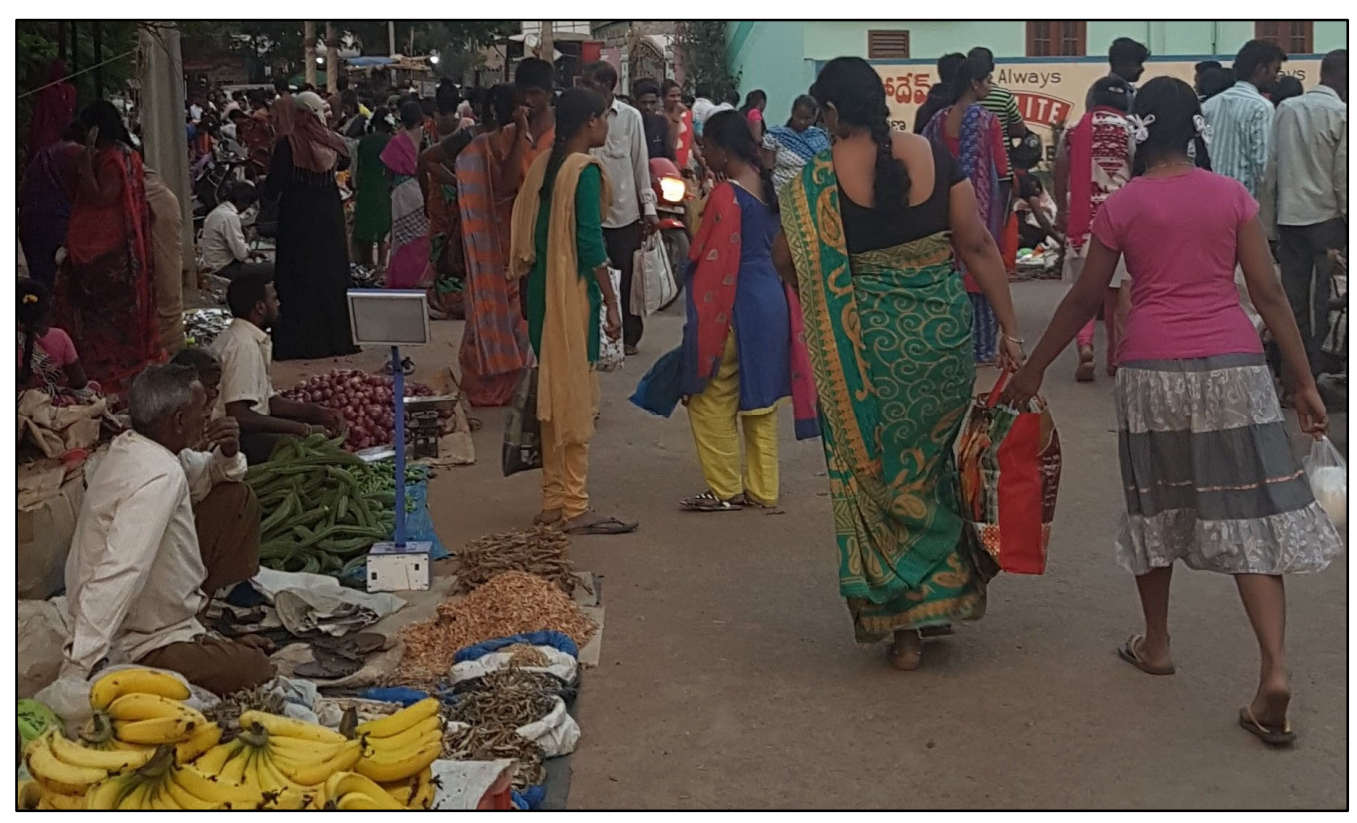

Figure 2. Wednesday Vegetable Market, Gagillapur (Picture by the author)

Social and cultural connections influence place belonging and are an integral part of any individual's life (Antonsich 2010). However, in India, due to the vast language and cultural differences within the country, migrants often experience social isolation while being identified as an outsider. These factors impact the migrant's sense of belonging in their new homes. Social interactions integrated as pauses in-between core activities, therefore, helped the women develop place-belonging by identifying other groups with similar interests in their neighbourhood and by establishing habit fields through their collective spatial use.

\section{Missed pauses in the times of a pandemic}

In response to the pandemic, on March $24^{\text {th }}, 2020$, the Indian government issued a nationwide lockdown for a 21 -day period, which was subsequently extended multiple times until May. These restrictions were subsequently eased in phases based on the change in the pandemic situation across the country. As part of the initial restrictions, all international and domestic movement ceased, public gatherings were banned, and a curfew on non-essential movement was enforced between $7 \mathrm{pm}$ and $7 \mathrm{am}$. The movement of autorickshaws, taxis and buses were also stopped in Hyderabad due to stringent rules.

The lockdown restrictions have impacted the time-spaces routines of every individual, especially the poor and marginalised people in the informal sector in India, who have lost income and housing. Further, due to mobility restrictions, several migrant workers were stranded, displaced and also unable to return home. 
In Gagillapur, most of the participants were financially dependent on their spouses who worked in the factories or service sector jobs. Due to the lockdown, several individuals would have either lost their jobs or suffered reduced working hours due to staggered shifts, resulting in financial distress at the household level. Further, with the closure of schools, most women were likely to experience an increase in responsibilities as caregivers when families were confined to their homes. Seeking entry into formal or informal employment to mitigate financial stress would also be difficult for the participants due to their busy schedules, limited educational qualifications in addition to restricted mobility and limited jobs in turbulent times. The increased stress over health, possible loss of jobs (or reduced income), lack of security within the household, coupled with mobility restrictions, could have possibly increased the likelihood of domestic violence occurrence in the private sphere.

For the migrant women in Gagillapur, missed pauses could translate into lost opportunities for relaxation, social interactions and time for self with increased stress and vulnerabilities at home, while they continue to fulfil gender norms as primary caregivers and experience restrictions from structures of power operating in both public and private spheres.

Citing Snow and Brissett (1986, p.I), pauses "are an essential element of the social rhythm that demonstrates degrees of personal and community well-being and vitality". However, in the pandemic, the migrant women in Gagillapur were likely to experience dislocation in their rhythms, which is detrimental to their sense of belonging as migrants as well as women.

\section{References}

Antonsich, M. (2010) 'Searching for Belonging - An Analytical Framework', Geography Compass, 4(6), 644-659, available: http://dx.doi.org/I0.1III/j.1749-8198.2009.003 I7.x.

Census of India (20II) CensusInfo India Dashboard, available: https://censusindia.gov.in/20I Icommon/censusdata201I.html [accessed February 2019].

Davies, K. (2003) 'Responsibility and Daily Life: Reflections over timespace' in May, J. and Thrift, N., eds., Timespace: geographies of temporality Routledge, I33-I48.

Law, R. (1999) 'Beyond 'women and transport': towards new geographies of gender and daily mobility', Progress in Human Geography, 23(4), 567-588.

Phadke, S., Khan, S. and Ranade, S. (201I) Why loiter?: Women and risk on Mumbai streets, Penguin Books India.

Rose, G. (1993) 'Women and Everyday Spaces' in Feminism and geography : the limits of geographical knowledge Polity Press, 17-40.

Snow, R.P. and Brissett, D. (1986) 'PAUSES: EXPLORATIONS IN SOCIAL RHYTHM', Symbolic Interaction, 9(I), I- I8, available: http://dx.doi.org/I0.I525/si.I 986.9.I.I.

Tuan, Y.-F. (1979) 'Space and place: humanistic perspective' in Gale, S. and Olsson, G., eds., Philosophy in Geography.Theory and Decision Library (An International Series in the Philosophy and Methodology of the Social and Behavioral Sciences) Springer, 387-427.

Whitzman, C. (2013) 'Women's safety and everyday mobility' in Whitzman, C., Legacy, C., Andrew, C., Klodawsky, F., Shaw, M., Viswanath, K., ed., Building inclusive cities women's safety and the right to the city, Routledge, 35-52. 